\title{
A LEITURA DE MONTEIRO LOBATO POR ACADÊMICAS DE LICENCIATURAS: RESULTADOS DE UM BREVE INQUÉRITO'
}

Luciane Maria Wagner Raupp ${ }^{2}$

\section{RESUMO}

Monteiro Lobato é apontado, em pesquisa publicada no ano de 2008 pelo Instituto Pró-Livro, como um dos escritores mais conhecidos do Brasil. No entanto, ser conhecido, neste caso, não significa ser mais lido, uma vez que as obras infantis lobatianas, adaptadas sucessivamente para seriados televisivos desde a década de 1950, ganharam visibilidade que transcende as suas páginas. Entendendo que a leitura de autores infantis e juvenis é influenciada diretamente pelas leituras prévias dos professores a fim de que possam indicá-las, procedeu-se a uma pesquisa de campo com acadêmicas dos cursos de Pedagogia e de Letras a fim de levantar como se deu o contato dessas futuras professoras com o universo ficcional do Sítio do Picapau Amarelo. Os dados obtidos confirmaram o impacto das adaptações televisivas sobre o imaginário construído em torno do autor e de suas obras direcionadas ao público infantil, mostrando que Monteiro Lobato é um autor extremamente conhecido, mas pouco lido.

Palavras-chave: Monteiro Lobato. Sítio do Picapau Amarelo. Visibilidade. Leitura nas Licenciaturas.

\section{ABSTRACT}

According to a research published by Instituto Pró-Livro in 2008, Monteiro Lobato is one of the most popular writers in Brazil. However, the fact of being well-known does not mean having his work widely read, as a result of his children's books being adapted for TV shows since the 1950's and gaining a visibility that still transcends the pages he wrote. Considering that the recommendation of young adult as well as children's literature is directly influenced by what teachers have previously read, a field survey among

\footnotetext{
${ }^{1} \mathrm{O}$ título do presente ensaio alude ao título de uma das obras de Monteiro Lobato dirigidas ao público adulto: O Saci Pererê: resultado de um inquérito. O motivo de tal escolha revelar-se-á ao final do texto.

2 Doutora em Letras/Teoria da Literatura. Professora das Faculdade Integradas de Taquara (Faccat)/RS. lucianeraupp@gmail.com.
} 
Language, Literature and Linguistics as well as Pedagogy students was developed to understand how these future teachers got acquainted with Sítio do Pica Pau Amarelo (Yellow Woodpecker Ranch) fictional universe. Data obtained from the survey have validated the significant impact of television adaptations on how the image of Monteiro Lobato and his books for children is built, proving that although he is very popular writer, his books are not extensively read.

Keywords: Monteiro Lobato. Sítio do Picapau Amarelo. Visibility. Licentiate students' reading.

\section{CONSIDERAÇÕES INICIAIS: A NOTORIEDADE DE LOBATO}

Monteiro Lobato é um dos escritores mais conhecidos no Brasil - fato comprovado pelos dados da pesquisa Retratos da Leitura II, realizada em 2007 pelo Instituto Pró-Livro e publicada em 2008 sob o título Retratos da Leitura no Brasil (AMORIM, 2008). Nessa pesquisa, o autor figura como primeiro colocado na lista de "Escritores brasileiros mais admirados pelos leitores" (idem, p. 178), seguido por Paulo Coelho, Jorge Amado e Machado de Assis. Esses quatro autores mais votados, de acordo com a observação que segue a referida listagem, receberam quase a metade do total de indicações.

Outro dado da pesquisa que aponta para o reconhecimento do autor junto aos leitores brasileiros diz respeito aos resultados obtidos acerca do questionamento sobre os livros mais importantes na vida dos entrevistados: "O Sítio do Pica-Pau Amarelo" figura como segundo colocado, logo após a Bíblia Sagrada. Como observação a respeito desse título, a pesquisa pondera que "Embora não conste da bibliografia brasileira, é uma referência à obra de Monteiro Lobato 3 " (idem, p. 179).

A "referência" à obra da qual nos fala a pesquisa remete-nos à conhecida afirmação de que Monteiro Lobato é um escritor muito conhecido, mas pouco lido. Essa popularidade, como sabemos, deve-se não apenas à qualidade das obras destinadas ao público infantil do autor ${ }^{4}$, mas também - e, hoje em dia, principalmente - às sucessivas adaptações televisivas. Isso vem ao encontro do que afirma Zilberman (2005, p. 21-22) acerca do autor:

Um escritor é muito popular quando o mundo que criou escapa a seu controle, como se as personagens vivessem independentemente dele. [...] Hoje, porém, vende-se a boneca Emília em lojas e supermercados, e o sítio aparece diariamente na tela dos aparelhos de televisão. [...] Jogos, brincadeiras, concursos - eis algumas atividades do cotidiano em que se recorre ao universo concebido pelo escritor, mostrando que a realidade fabulosa que saiu de sua cabeça acabou sendo mais duradoura do que ele mesmo cogitou.

\footnotetext{
3 Registramos a existência da obra de Lobato intitulada "O Picapau Amarelo" (1939), com o nome do pássaro grafado sem hífen. Já o título indicado pelos entrevistados, "O Sítio do Pica-Pau Amarelo", faz clara referência ao seriado televisivo, exibido pela Rede Globo nos anos de 1970 e 1980, reprisado pela TV Cultura na década de 1990 e produzido novamente entre os anos de 2001 e 2007. Ressaltamos o fato de que, na época da pesquisa, a série ainda estava sendo exibida.

4 Lobato foi um escritor popular antes mesmo de sua morte, em 1948, dois anos antes da primeira transmissão televisiva no Brasil, que ocorreu em 18 de setembro de 1950, e da primeira adaptação das suas obras infantis a esse meio, com o teleteatro da TV Tupi.
} 
A notoriedade, a durabilidade e a permeabilidade do universo infantil lobatiano apontadas por Zilberman no excerto, produzidas pela exposição da obra em um meio de comunicação de massa ${ }^{5}$, conduzem-nos a pensar sobre as motivações extraliterárias que poderiam levar, atualmente, à leitura das obras infantis do autor. Acerca dessas motivações, Escarpit (1974, p. 37) afirma que a obra literária, de modo geral, tende a captar leitores "[...] mediante motivaciones no literárias: habitos, esnobismo, consumo ostentoso, culpabilización cultural [...]". Isso explicaria, pelo menos em parte, o fato de Monteiro Lobato ser citado na referida pesquisa: como sua obra estava em evidência na mídia - portanto no topo do sistema de consumo, segundo a lógica do capitalismo -, ele deveria, ao menos em tese, ser lido. Nesse ponto, entra a citada culpabilização cultural de que nos fala Escarpit (1974), como se a leitura de Lobato deveria ser feita como que para suprir "[...] las represiones sociales que crean en el lector la necessidad de calmar las obsesiones semiinconscientes de una inseguridad estadisticamente ponderable [...]" (loc. cit.). Assim, uma hipótese para o fato de os entrevistados afirmarem admirar Monteiro Lobato e ter lido a obra "Sítio do Pica-Pau Amarelo", título improcedente, que denunciaria a não leitura, residiria na imagem de si que os pesquisados gostariam de construir frente aos pesquisadores. Essa simulação de leitura de Lobato, até certo ponto factível pelo contato com as adaptações televisivas, de certa forma, derivaria dos mesmos antigos motivos descritos por Darnton (1996, p. 404) que faziam com que, no século XVIII, certo público adquirisse a Enciclopédia in quarto, uma vez que a ter na estante "[...] proclamaria a posição de seu proprietário como homem culto e filósofo". Ou seja, embora a declaração dos entrevistados como leitores e admiradores de Lobato não os alce à condição de parecerem ser filósofos, coloca-os no rol dos portadores de leituras clássicas - portanto, em um raciocínio baseado nas aparências, presumivelmente cultos.

No mesmo documento em que se constata a presença de destaque de Monteiro Lobato, também se aponta a escola como lugar de influência nos hábitos de leitura. De acordo com a citada pesquisa, dos leitores de livros no Brasil, "47,4 milhões (50\%) dos leitores são estudantes que leem livros indicados pelas escolas (inclusive os didáticos)" (AMORIM, 2008, p. 167). Reforçando essa estatística da leitura escolar, temos, na mesma pesquisa, as informações de que, entre as leituras que os entrevistados estavam realizando no momento da pesquisa, $34 \%$ liam livros recomendados pela escola (Idem, p. 175) e a de que a parcela maior de leitores, classificando-se por idade, encontra-se na faixa dos 5 anos 10 anos (Idem, p. 167), com 16\% do total dos leitores. Assim, grosso modo, podemos vincular ainda mais estreitamente a leitura ao convívio no ambiente escolar. Isso posto, o caminho é pensarmos nos mediadores da leitura na escola: os professores.

\section{A LEITURA PRÉVIA DE MONTEIRO LOBATO POR ACADÊMICAS DE LICENCIATURA EM LETRAS E PEDAGOGIA - UM BREVE INQUÉRITO}

Se a maior parte dos leitores é estudante, lê e compra livros indicados pela escola,

\footnotetext{
${ }^{5}$ Na pesquisa "Retratos da Leitura no Brasil", quando se perguntou o que os entrevistados mais gostavam de fazer em seu tempo livre, obteve-se, em primeiro lugar, o resultado "Assistir televisão", com 77 \% das repostas. Já a leitura, que poderia compreender outros suportes além do livro, aparece em quarto lugar.
} 
se Monteiro Lobato é um dos escritores mais lidos e se os professores são os mediadores dessa prática, isso, pela lógica, significaria que os professores fizeram a leitura prévia das obras desse escritor, seja na sua infância, seja no seu processo de formação. Dessa forma, a fim de testar a afirmação, entre um grupo de acadêmicas dos cursos de Letras e de Pedagogia, futuras professoras da Educação Básica ou já atuantes, de que Monteiro Lobato é um escritor muito conhecido mas pouco lido, fizemos uma pesquisa junto a 8 alunas do curso de Letras e a 20 do curso de Pedagogia das Faculdades Integradas de Taquara, matriculadas, no primeiro semestre de 2011, na disciplina intitulada Literatura Infanto-Juvenil, no horário de sábado pela manhã. Nessa pesquisa, além de constatar a leitura prévia (ou não) das obras, também buscamos investigar a influência, no grupo, das sucessivas adaptações televisivas do universo infantil lobatiano quanto à visibilidade e quanto ao incentivo à leitura das obras que compõem esse universo. O questionário aplicado também objetivou levantar os fatores que levam à leitura ou a não leitura das obras infantis de Lobato.

O questionário foi estruturado em quatro partes.

Na primeira, o objetivo era caracterizar as entrevistadas ${ }^{6}$.

Na segunda, procuramos dividi-las em dois grupos: as leitoras e as não leitoras de Lobato.

Já a terceira parte era destinada apenas às entrevistadas que se declararam não leitoras de Lobato, procurando pelos motivos que as levaram a não ler as obras lobatianas. Também buscamos investigar o contato desse grupo de não leitoras com as adaptações televisivas.

Por fim, na quarta parte, interrogamos as declaradas leitoras de Lobato quanto ao que as levou à leitura, quais foram as obras lidas, quais são as características ou fatos marcantes da(s) leitura(s), ou seja, quais são as suas "memórias de Lobato". Algumas perguntas foram deixadas no formato de respostas abertas a fim de que se pudesse fazer um maior controle sobre quem efetivamente leu Monteiro Lobato ou apenas assim se declarou a fim de manter certa "imagem pessoal", como já falamos acerca da pesquisa efetuada pelo Instituto Pró-livro. Além disso, também buscamos investigar relações que as entrevistadas estabelecem entre as obras e as adaptações televisivas.

\subsection{Perfil do grupo pesquisado}

Do universo de 28 acadêmicas, 11 declararam-se não leitoras de Lobato Dessas 11, 2 são do curso de Letras e nove do de Pedagogia. As 2 alunas de Letras não leitoras de Lobato são provenientes da rede pública de ensino. Uma delas cursou o Ensino Médio regular; a outra, o programa de Educação para Jovens e Adultos (EJA). Uma está com 25 anos e outra com 26. Apenas 1 leciona (para todas as séries do Ensino Fundamental e do Ensino Médio, em contrato emergencial do Estado), mas não informou a disciplina nem há quanto tempo está no magistério. A que não leciona está no $2^{\circ}$ semestre do curso; a que leciona, no $4^{0}$.

As 9 entrevistadas que cursam Pedagogia autodeclaradas como não leitoras de

${ }^{6}$ Optou-se por usar o termo no feminino, pois só havia alunas na turma pesquisada. 
Lobato também são provenientes da Rede Pública de Ensino. Duas cursaram EJA, 6 fizeram o Ensino Médio regular e 1 cursou a Habilitação ao Magistério. Cinco delas contam com idades entre 19 e 23 anos, e as outras têm 32, 46 e 54 anos. Cinco não lecionam. As outras 4 atuam na Educação Infantil, no berçário, com tempo de experiência variando entre 6 meses e 2 anos. Quanto ao semestre no curso, estão entre o $1^{\circ}$ e o $4^{\circ}$.

Já as alunas autodeclaradas leitoras de Lobato perfazem um total de 17. Dessas, 6 são alunas do curso de Letras e 11 de Pedagogia. Das 6 alunas de Letras, 3 estão no $2^{\circ}$ semestre do curso e 2 no terceiro. Uma delas não respondeu a esse item. As idades variam de 22 a 30 anos. Cinco cursaram o Ensino Médio regular na Rede Pública e 1 é egressa do EJA particular. Cinco não lecionam. Uma leciona na Educação Infantil e Especial há 3 anos. Já as alunas de Pedagogia estão em semestres diferentes do curso, do $1^{0}$ ao $6^{0}$. As idades variam entre 18 e 43 anos. Todas lecionam: Educação Infantil, 5 entrevistadas; séries iniciais do Ensino Fundamental, 3 respostas; aulas de reforço e acompanhamento, 3 respostas. 0 tempo de exercício docente varia de 3 meses a 15 anos.

Observamos, pelo perfil traçado, que o maior número de entrevistadas que declaram ter lido uma ou mais obras de Lobato encontra-se entre as que, apesar de não terem concluído o curso superior, já atuam como professoras. Entretanto, 5 entrevistadas que já lecionam declararam-se não leitoras de Lobato. Dentre essas, 5 trabalham no berçário.

\subsection{As não leitoras de Lobato}

As 11 alunas que declararam nunca ter lido obras de Monteiro Lobato afirmam já ter ouvido falar do leitor. A questão "Mesmo não tendo lido obra(s) de Lobato, como soube sobre o escritor? (Marque uma ou mais alternativas)" obteve 7 respostas tanto para a alternativa "Por meio de aulas teóricas no Ensino Médio ou na Faculdade" quanto para a alternativa "Por meio dos seriados da televisão". Também obteve destaque a alternativa "Meus professores contavam as histórias do Sítio", com 5 respostas. Há que se destacar os comentários "Através de palestras", "Contato com as obras ao trabalhar na biblioteca pública do meu município" e "Minha filha de 7 anos estudou sobre ele na escola e eu tive que ajudá-la". Constatamos, portanto, que o universo infantil lobatiano foi retransmitido para esse grupo de uma maneira fortemente oral e escolar (aulas teóricas, palestras e narração de histórias) e também pelas adaptações televisivas e por tarefas do cotidiano (na profissão de atendente de biblioteca e no seu papel de mãe). Todavia, essas demandas não se mostraram suficientes para que as entrevistadas se sentissem, de fato, motivadas ou obrigadas a ler as obras, como se as informações obtidas esparsamente fossem suficientes para as tarefas pontuais.

Em relação às informações que as entrevistadas têm do universo infantil lobatiano, indagadas por meio da pergunta "Das informações que você tem sobre Monteiro Lobato e sua obra infantil, o que Ihe chama atenção ou conserva na memória?", para a qual elas poderiam marcar uma ou mais alternativas ou ainda fazer anotações na alternativa “Outros. Quais?", destacamos a presença das personagens Emília (10 respostas) e Tia Nastácia (8 respostas). Como sabemos, Emília é a personagem mais popular do universo 
lobatiano, que, mesmo na época da pesquisa, em 2011, com o seriado fora da grade da programação da Rede Globo, a emissora mais popular do país, ainda se encontra em alta, figurando, por exemplo, como uma espécie de "garota-propaganda" de marcas de alimentos e comercializada pela marca Grow sob forma de boneca falante. Assim, a personagem - e, por extensão, o universo infantil lobatiano - entra no universo das marcas, em um fenômeno próximo ao que descreve Fraisse (2010) acerca das Produções Disney. Trata-se do que o autor (2010, p. 217, grifo do autor) aponta como uma das seis características da globalização em termos culturais: “[...] a oferta mundial dá-se sob a forma de produtos derivados destinados ao consumo sob múltiplas formas: livros, filmes, objetos, roupas, desenhos animados, logotipos, parecem emergir da mesma filosofia da mercantilização e das marcas". Além disso, a personagem, caracterizada de acordo com o figurino da versão televisiva de 2001, ainda está presente em festas escolares e infantis. No entanto, essa caracterização da personagem, de modo a atender às demandas mercadológicas, desvia-se da caracterização feita nas obras literárias, especialmente em "Reinações de Narizinho", as quais a descrevem como uma boneca feia, feita de retalhos de uma saia velha de Tia Nastácia, embora em constante mutação.

Essa transmissão do universo lobatiano pelas adaptações televisivas é confirmada por meio dos resultados obtidos com a pergunta "Você assistia ao seriado televisivo intitulado 'O Sítio do Picapau Amarelo'?". Houve 5 respostas para a alternativa "Sim, a versão dos anos 2000" e 4 para a "Sim, mas não sabia, na época, que era baseado na obra infantil de Monteiro Lobato". Duas entrevistadas marcaram a opção "Sim, ainda assisto à reprise pelo Canal Futura" e apenas 1 marcou a alternativa "Sim, a versão dos anos 1970 e 1980". Ninguém marcou as opções "Não", "Sim, a versão dos anos 1970 e 1980 reprisada pela TVE na década de 1990" ou "Assisti por outros meios. Quais?". Esses resultados confirmam, no grupo pesquisado, a conhecida influência e o alcance da Rede Globo, uma vez que as entrevistadas assistiram ao seriado quando veiculado por ela ou ainda assistem pelo canal dito "educativo" dessa mesma rede, o Canal Futura, excluindo-se a TVE7 ou mesmo outros meios, como DVDs e internet.

No entanto, quando perguntadas se "Há algum fato, personagem ou característica marcante que lhe ficou gravada na memória a partir do seriado televisivo?", os resultados obtidos apontam para certa liquefação dos conteúdos televeiculados. Nove entrevistadas responderam negativamente a essa questão, enquanto apenas 2 descreveram como marcantes o que segue: "Lembro de um episódio que chamou quando o Pedrinho subia numa árvore, que tinha uma casinha para ele e a Emília brincar." e "O Saci, porque nas historinhas para mim era um símbolo feio, e na televisão teve uma imagem oposta.".

Tais respostas imprecisas mostram uma tendência de liquefação, de apagamento, com o decorrer do tempo, das histórias narradas nos episódios televisivos - fato que é peculiar a esse suporte, efêmero por excelência, seguindo a lógica do capitalismo: consumir, descartar, consumir novamente. Desse modo, podemos afirmar que esse grupo de telespectadoras do "Sítio do Pica-Pau Amarelo" sabe da existência de Monteiro

\footnotetext{
${ }^{7}$ No Rio Grande do Sul, o seriado foi veiculado pela emissora do estado, que tinha (e ainda tem) dificuldades técnicas de atingir todas as cidades do interior - muito diferente do que ocorre com a Rede Globo.
} 
Lobato e dos personagens por ele criados, entretanto nunca leram as obras, tampouco guardam lembranças significativas do que assistiram.

Quanto aos motivos que as levaram a não leitura das obras de Monteiro Lobato, o maior número de respostas obtidas foi para a alternativa "Nunca me foi solicitado" (5 respostas), seguida de "Não tive acesso aos livros de Monteiro Lobato na biblioteca de minha escola" (3 respostas) e de "Comecei e achei a linguagem difícil" (1 resposta). Duas entrevistadas também registraram "Nunca gostei de ler" e "Não tenho tempo de ler", o que é alarmante, ainda mais em se tratando de futuras professoras. Nenhuma entrevistada marcou as opções "Comecei e não achei a história atraente", "Vi os livros na biblioteca e não os achei interessantes." ou "Como assistia ao seriado na televisão, considerava que não era necessário ler os livros".

Essas respostas desmentem, pelo menos nesse grupo, a fala corrente de que a linguagem de Monteiro Lobato é o maior entrave à leitura (apenas uma entrevistada apontou isso), deixando-a desinteressante, de que as capas das edições anteriores desmotivavam os alunos ou de que a teledifusão das adaptações televisivas também desestimulam a leitura de Lobato. Nesse grupo, a não leitura se deve a questões mais graves, porém amplamente conhecidas, da própria estrutura do ensino: a falta de criação do hábito de leitura e de um trabalho sistemático e pontual da leitura literária aliada às condições das bibliotecas escolares.

\subsection{As leitoras de Lobato}

Já as 17 declaradas leitoras de Lobato, quando questionadas acerca de quando leram as obras desse autor ${ }^{8}$, leram-nas no Ensino Fundamental (séries iniciais, 7 respostas; séries finais, 2 respostas), no Ensino Médio (5 respostas, 2 delas observando "quando faziam o Magistério") e no Ensino Superior ( 7 respostas $^{9}$, sendo 3 na disciplina de Literatura Infanto-Juvenil, 3 por conta própria). Chama-nos a atenção o grande número de respostas que envolvem a leitura acadêmica, como parte da formação do professor, no antigo curso de Habilitação ao Magistério e/ou no Ensino Superior, perfazendo um total de 12 resultados.

No que diz respeito ao incentivo à leitura das obras lobatianas, 5 entrevistadas disseram-se motivadas pelos professores. Quatro assinalaram a alternativa "Senti-me motivado(a) pelo seriado televisivo" e 2 escolheram a resposta "Fui motivado(a) pelos meus pais/familiares". Também 2 marcaram a opção "Tratava-se de leitura obrigatória. Em qual série/nível?", explicitando que isso se deu "Na disciplina de Literatura Infanto-Juvenil"10 ou "No terceiro ano do Magistério". Outras 5 assinalaram a opção "outros" e explicitaram:

\footnotetext{
${ }^{8}$ As entrevistadas poderiam assinalar mais de uma alternativa.

9 Uma das entrevistadas ainda observou que "Quando me matriculei na disciplina de Literatura Infanto-Juvenil, soube por colegas que a professora era muito exigente e que Lobato seria trabalhado e durante as férias li toda a sua obra. Quanto mais lia, mais queria ler".

${ }^{10}$ Cabe destacar que a pesquisa foi feita antes de a leitura de Monteiro Lobato ser solicitada às alunas. Também ressaltamos o fato de haver alunas que estavam repetindo a disciplina.
} 
- Curiosidade.

- Já gostava do seriado e descobri que a leitura é mais fantástica ainda.

- Gosto de ler, a leitura para mim é um prazer, então leio tudo que me digam que seja bom. Resolvi pesquisá-lo quando assumi a biblioteca na escola que trabalho, chamada 'Monteiro Lobato', para apresentá-lo aos alunos.

- Senti necessidade de conhecer melhor a biografia e as obras de Monteiro Lobato pelo fato de ter sido uma abordagem muito vaga no Magistério e pelo fato de ser uma leitura muito interessante às crianças e a nós também.

Desse modo, percebemos, mais uma vez, nas duas últimas respostas, a escolarização da leitura de Lobato, já que 5 entrevistadas declararam-se motivadas pelos professores, 2 leram por obrigações escolares/acadêmicas e outras 2 relataram a motivação à leitura devido a imperativos da profissão - bibliotecária de escola ou professora.

O primeiro contato das entrevistadas com o universo infantil lobatiano foi, para a maioria, por meio da série televisiva (9 respostas), seguida pela leitura das obras (4 respostas) e pela narração por adultos (3 respostas). Quanto às obras de Lobato lidas pelas entrevistadas, destacou-se "Reinações de Narizinho"11, com 7 respostas. Em seguida, temos, com 2 respostas cada, as obras "Emília no país da gramática", "O Saci", "Memórias de Emília" e "Sítio do Pica-Pau Amarelo". Sobre esse último título, assinalamos que vem ao encontro do que se encontrou na pesquisa "Retratos da leitura no Brasil" anteriormente mencionada e comentada. Nessa mesma esteira de títulos imprecisos ou errôneos, encontramos as seguintes respostas: "Alice ${ }^{12}$ no país das maravilhas e outros", "Hércules ${ }^{13}$ e Minotauro" e "Histórias de Tia Anastácia"14". Obtivemos também uma resposta mais imprecisa, que transcrevemos: "Não me lembro de nomes de livros, mas lembro-me de trabalhar muito sobre o surgimento dos personagens do Sítio do Picapau Amarelo após a biografia do autor, que se faz necessária para o entendimento das criações". Nessa resposta, talvez tenhamos encontrado o reflexo de um modelo de ensino que privilegiava os dados contextuais e biográficos em detrimento da leitura em si, já que a entrevistada sequer lembra dos títulos das obras que supostamente leu.

Em relação às lembranças que ficaram das leituras, solicitadas por meio da pergunta "Qual a lembrança que ficou dessa(s) leitura(s)?", são citadas em número bem menor do que as provenientes da questão "Há algum fato, personagem ou característica marcante que Ihe ficou gravada na memória a partir do seriado televisivo?". Em relação às memórias da leitura, assinalaram, em primeiro lugar, as personagens ( 10 respostas) e em segundo, o enredo (9 respostas). Houve 5 escolhas da alternativa "O enredo e a linguagem

\footnotetext{
${ }^{11}$ A leitura dessa obra já estava prevista no cronograma da disciplina entregue na primeira aula do semestre.

${ }^{12}$ A personagem Alice, da obra de Lewis Carroll, visita o Sítio, porém Lobato sequer adaptou a obra.

${ }^{13}$ Lobato adaptou "Os doze trabalhos de Hércules". No entanto, não há obra intitulada exatamente como "Hércules e Minotauro", como registrou a entrevistada, mas, pela editora Brasiliense, há duas obras distintas intituladas, respectivamente, "O Minotauro" e "Os doze trabalhos de Hércules". Quanto a este último, a Brasiliense publicou em dois tomos, dividindo os trabalhos em de 1 a 6 e de 7 a 12. Já a Globo Marcas lançou, em 2009, um DVD com episódios da temporada dos anos 1970, intitulado "O Minotauro".

${ }^{14} \mathrm{Se}$ a leitura tivesse ocorrido, e não apenas ouvido o nome no seriado, talvez esse erro de grafia não acontecesse.
} 
eram de fácil acesso." e 4 da opção "O enredo era bom, mas a linguagem era difícil". Em relação aos comentários extras, obtivemos apenas 2 - e bastante vagos, que poderiam ser feitos em relação a quaisquer outras obras infantis de sucesso: "Conseguia me imaginar dentro da narrativa" e "Uma linguagem adequada para as crianças, uma leitura divertida e agradável". Já em relação às memórias deixadas pelo seriado televisivo, ao qual todas assistiram, especialmente a versão dos anos 2000 (12 respostas), o número de comentários foi bem mais expressivo: 15 respostas. Dessas 15, 9 mencionaram a personagem Emília - uma, inclusive, chamando-a de "A menina Emília" (grifo nosso). Outras personagens bastante citadas (5 vezes cada) foram a Cuca e a Tia Nastácia, ou "Anastácia", como o nome foi grafado em 3 respostas. Destacamos também a resposta "Tia Anastácia, pois, apesar de tanto tempo e tantas adaptações ocorridas, ela é um dos poucos personagens que ainda transmitem ternura, graça, zelo, amor, como Monteiro Lobato transmitia”, em que se estendem as memórias afetivas da infância à figura do escritor.

Outra resposta que nos chamou a atenção, mostrando o lugar privilegiado do seriado televisivo na infância da entrevistada, foi a seguinte: "Comentário referente à versão antiga: Sim, praticamente todos, o Visconde, a Emília (que minha mãe comparava comigo, pois falava pelos cotovelos), dona Benta, Tia Anastácia com seus quitutes e guloseimas (a qual comparava com minha mãe), as diversas aventuras dos primos Pedrinho e Narizinho, enfim, gostava bastante de olhar a primeira versão do Sítio. A segunda versão (mais atual) pouco assisti e até me fez perder um pouco do interesse". Fica-nos a pergunta: esse interesse ao qual a entrevistada se referiu seria em relação ao seriado ou às obras literárias?

No que diz respeito à relação entre as obras e as adaptações televisivas, apenas uma entrevistada assinalou preferir os seriados, e outra assinalou a opção "As obras literárias decepcionaram-me, pois o seriado televisivo é bem melhor". A alternativa "Prefiro a obra literária ao seriado televisivo" foi assinalada 8 vezes, seguida de "O seriado televisivo decepcionou-me, pois as obras literárias são melhores" (4 respostas) e de "O seriado televisivo não é fiel à obra literária" (também 4 respostas). Outras 7 constatações foram registradas. Quatro delas são tão genéricas que talvez servissem para qualquer adaptação televisiva, como transcrevemos abaixo:

- Pois na obra a riqueza dos detalhes é mais perceptível.

- Quando se lê um livro primeiro e depois passa-se a observá-lo na televisão, se tem outra visão que às vezes nos decepciona, pois imaginamos os personagens de forma diferente a que nos são apresentadas.

- Cada versão tem sua razão de ser, a TV mesmo que quisesse não conseguiria reproduzir a obra fiel, mas tenta adaptar da melhor forma possível para as crianças.

- A obra traz uma riqueza de detalhes que no seriado televisivo são perdidos ou distorcidos.

- Gosto tanto do seriado quanto da obra.

Há, ainda, outra resposta que evidencia a imprecisão da memória acerca do seriado exibido nas décadas de 1970 e 1980: “A versão dos anos 1970 e 1980 é muito bem representada, tratando os valores de forma adequada e coerente. A versão dos anos 2000 traz uma Emília respondona, mal-educada, sem respeito nem limites". Outra ideia 
incorreta acerca de Emília, se considerarmos o modo como é caracterizada nas obras, encontramos na seguinte resposta: "Após conhecer a obra de Monteiro Lobato escrita, pude perceber 'adaptações' equivocadas, como por exemplo, a Emília, uma boneca malcriada diferentemente da Emília simpática e companheira das narrações de Monteiro Lobato". Essas respostas, naturalmente, levam-nos a questionar se realmente todas as 17 entrevistadas que declararam já ter lido alguma obra de Monteiro Lobato realmente o fizeram.

\section{CONSIDERAÇÕES FINAIS: O “(DES)ENSACIZAMENTO” DE LOBATO}

Não se pode negar que, para o cidadão médio brasileiro, em conversas triviais, é muito fácil falar do universo infantil lobatiano - afinal, ele permeia o imaginário nacional especialmente pela visibilidade auferida com as sucessivas adaptações televisivas. No entanto, o Lobato que se vê não é o mesmo que se lê. De certa forma, esse Lobato massificado é uma espécie de "Saci"15 de nossos dias: faz parte do imaginário popular e sabe-se dele pelos relatos alheios (hoje, pela TV, palestras, aulas). Embora alguns digam tê-lo visto (ou lido, no caso de Lobato), sempre pairou e paira a dúvida acerca da veracidade e das intenções desses depoimentos.

Diríamos, por isso, que, a fim de "desensacisarmos" não só as obras de Lobato, com o perdão do necessário neologismo, mas também as de outros autores que vieram ou virão a passar pelos inevitáveis processos de adaptação para outras mídias, torna-se necessário, segundo Figueiredo (2010, p. 268), “[...] estudos que privilegiem os diálogos e as tensões que se estabeleceram, ao longo do tempo, entre o campo literário e outras práticas culturais, como o jornalismo, as produções cinematográficas ou a cultura midiática em geral". Além de estudar essas relações apontadas pela autora, há que se pesquisar como essas adaptações têm impactado os hábitos de leitura, especialmente no que se refere às adaptações televisivas de obras literárias - consagradas ou não.

No caso específico de Monteiro Lobato, sabemos que, mesmo antes do teleteatro da TV Tupi, em 1950, suas obras infantis, guardadas as devidas proporções, já eram best-sellers. Isso nos leva a afirmar que essa incorporação televisiva do universo do Sítio se deu baseada na perspectiva do sucesso anterior no meio impresso. Desse modo, é possível dizer que a incipiente televisão brasileira utilizou estratégias de lucro que lembram as dos primeiros livreiros, no século XV, na recém-surgida imprensa. Esses livreiros trataram de "[...] difundir mais ainda os textos que já haviam tido grande sucesso enquanto manuscritos" (FEBVRE; MARTIN, 1992, p. 356-357). Seguindo essa mesma lógica, séculos depois, a televisão brasileira adaptou os best-sellers de Lobato, em um movimento similar ao que descreve Figueiredo (2010, p. 271) acerca das adaptações feitas pelos estúdios cinematográficos de Hollywood na década de 1960: “Além de já ter sido aprovado pelo gosto popular, o 'best-seller' ainda emprestaria ao meio cinematográfico a 'superioridade do meio livresco'".

Portanto, em síntese, adaptar Lobato às telas de TV tem sido, através das décadas,

\footnotetext{
$\overline{{ }^{15} \text { Sobre esse personagem }}$ da nossa mitologia, Lobato, em 1918, lançou o resultado de um inquérito, que reuniu 311 depoimentos sobre o Saci, vindos de diferentes cidades do Sudeste.
} 
garantia de audiência e de lucro. Contudo, essas adaptações e readaptações acabam perdendo as referências das origens literárias sem, contudo, admitir essa perda. É como afirma Escarpit (1974, p. 39): “Las adaptaciones cinematográficas, radiofônicas y, sobre todo, televisadas han influído profundamente la vision de la literatura. [...] El reportaje y la publicidad popularizan al escritor y su obra como a cualquier marca comercial".

Devido a essa popularização, aos entrevistados, tanto os da pesquisa "Retratos da leitura no Brasil", quanto os do breve e modesto inquérito aqui relatado, foi fácil e cômodo dizer que leram as obras de Monteiro Lobato, uma vez que possuem algumas informações sobre elas e as reconhecem como importantes, pela referida "superioridade do meio livresco". No entanto, como conclusão e diretriz para futuras ações, vale lembrarmos das palavras de Zilberman (2005, p. 22): “De certo modo, nem se precisaria ler a obra de Lobato para conhecer as principais personagens ou o cenário em que elas viveram. Mas se lida, esclarece-se por que ela ficou famosa e, de troco, ainda se obtém grande prazer pessoal, resultante da qualidade dos livros elaborados por ele".

\section{REFERÊNCIAS}

AMORIM, Galeno (Org.). Retratos da Leitura no Brasil. São Paulo: Imprensa Oficial; Instituto Pró-livro, 2008. Disponível em: <http://www.prolivro.org.br/ipl/publier4.0/ dados/anexos/1815.pdf>. Acesso em: 16 jun. 2011.

DARNTON, Robert. O iluminismo como negócio. História da publicação da "Enciclopédia", 1775-1800. São Paulo: Companhia das Letras, 1996.

ESCARPIT, Robert. Hacia una sociologia del hecho literário. Madrid: Edicusa, 1974.

FEBVRE, Lucien; MARTIN, Henri Jean. O aparecimento do livro. São Paulo: Hucitec, 1992.

FIGUEIREDO, Vera Lúcia Follain de. Literatura e comunicação audiovisual: uma história de interseções e deslocamentos. In: MOREIRA, Maria Eunice (Org.). Histórias da literatura: teorias e perspectivas. Porto Alegre: Edipucrs, 2010. p. 267-279.

FRAISSE, Emmanuel. Numeralização e mundialização: quais são os impactos sobre a literatura infantojuvenil? In: AGUIAR, Vera Teixeira de; CECCANTINI, João Luís (Orgs.). Teclas e dígitos: leitura, literatura \& mercado. São Paulo: Cultura Acadêmica, 2010.

ZILBERMAN, Regina. Como e por que ler a literatura infantil brasileira. Rio de Janeiro: Objetiva, 2005. 